\title{
Percepções de professores/as sobre as diferenças de género na educação em sexualidade em escolas portuguesas
}

\author{
Teresa Vilaça \\ Instituto de Educação da Universidade do Minho, Braga, Portugal \\ tvilaca@ie.uminho.pt
}

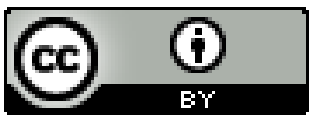

Educação: teoria e prática, Rio Claro, SP, Brasil - elSSN: 1981-8106

Está licenciada sob Licença Creative Common

\section{Resumo}

Argumenta-se que de acordo com as percepções dos/as professores/as os/as estudantes usam ativamente o material de educação em sexualidade (ES), bem como os aspetos da vida na escola, como recursos simbólicos para construir a sua identidade de género e as suas relações de poder. Neste sentido, aplicou-se uma entrevista semiestruturada a uma amostra intencional de professores/as, que lecionam entre o 70 e o 12ㅇaㅇ anos de escolaridade e já desenvolveram projetos ou atividades de ES ( $\mathrm{N}=87)$, para focar, entre outros aspetos, as suas percepções sobre as características de género que afetam a resposta dos/as estudantes na ES, visando conhecer as suas percepções sobre: i) diferenças de género nas reações aos temas/problemas da ES; ii) natureza das interações de género durante a ES. De acordo com o discurso da maior parte dos/as professores/as, durante a ES os rapazes tentaram demostrar a sua masculinidade mostrando-se diferentes das raparigas e distanciando-se de todos os assuntos relacionados com a sexualidade das mulheres, desvalorizando e afastando-se de tudo o que é feminino o que envolveu, por vezes, depreciar e insultar as raparigas. As alunas reagiram positivamente porque a ES mantém e apoia o seu sentido de identidade de género e o que os códigos de género prescrevem para elas. Estes resultados revelam que é essencial trabalhar na formação de professores/as a relação entre género, sexualidade e poder para ficarem capacitados para refletir criticamente sobre as reações dos/as alunos/as no sentido de promover a equidade de género.

Palavras-chave: Género. Identidades de género. Relações de poder. Professores. Alunos

\section{Teachers' perceptions on gender differences in sexuality education in Portuguese schools}

\author{
Abstract \\ It is argued that according teachers' perceptions, boys and girls actively use the \\ material on sexuality education (SE), as well as the aspects of school life, as symbolic
}


resources to construct their gender identity and their power relationships. In this sense, an investigation where a semi-structured interview was applied to a purposeful sample of teachers who were teaching between the 7th and 12th years, and who had already developed projects or activities of SE $(\mathrm{N}=87)$ will be presented, to focus on, among other aspects, their perceptions regarding issues related to gender that affect the responses of students in sexuality education, aiming at understanding their perceptions on: i) gender differences in students' reactions to themes/problems of SE; and ii) the nature of the gender interactions during SE. According to the discourse of most teachers, during SE, boys tried to demonstrate their masculinity by presenting themselves differently to girls and distancing themselves from all matters related to women's sexuality, devaluating and distancing themselves from all that is feminine which sometimes involved belittling and insulting the girls. However, the girls reacted positively because SE maintains and supports their sense of gender identity and gender codes that are prescribed for them by society. Therefore, these results show that it is essential to work in teacher training on the relationship between gender, sexuality and power in order to empower teachers to reflect critically on students' reactions to promote gender equity.

Keywords: Gender. Gender Identities. Power relationships. Teachers. Students

\section{Percepciones de profesores/as sobre las diferencias de género en la educación en sexualidad en escuelas portuguesas}

\section{Resumen}

Se argumenta que, de acuerdo con las percepciones de los profesores/as, los/las estudiantes usan activamente el material de educación en sexualidad (S), así como los aspectos de la vida en la escuela, como recursos simbólicos para construir su identidad de género y sus relaciones de poder. En este sentido, se aplicó una entrevista semiestructurada a una muestra intencional de profesores/as, que dan clase entre el 70 y el 12으os de escolaridad y ya desarrollaron proyectos 0 actividades de ES $(\mathrm{N}=87)$, para enfocar, entre otros aspectos, sus percepciones sobre las características de género que afectan la respuesta de los estudiantes en la ES, teniendo como objetivo conocer sus percepciones sobre: i) diferencias de género en las reacciones a los temas/problemas de la ES; ii) naturaleza de las interacciones de género durante la ES. De acuerdo con el discurso de la mayoría de los/las profesores/as, durante la ES los chicos intentaron demostrar su masculinidad mostrándose diferentes de las chicas y distanciándose de todos los asuntos relacionados con la sexualidad de las mujeres, desvalorando y alejándose de todo lo que es femenino lo que implicó, a veces, depreciar e insultar a las chicas. Las alumnas reaccionaron positivamente porque la ES mantiene y apoya su sentido de identidad de género y lo que los códigos de género les prescriben. Estos resultados revelan que es esencial trabajar en la formación de profesores/as la relación entre género, sexualidad y para poder estar capacitados para reflexionar críticamente sobre las reacciones de los/las alumnos/as en el sentido de promover la equidad de género. 
Palabras clave: Género. Identidades de género. Relaciones de poder. Profesores. Alumnos.

\section{Introdução}

A discussão sobre o desenvolvimento sexual e a identidade de género na adolescência tem-se fundamentado nas redes conceptuais sobre a natureza da sexualidade e as suas ligações com o género (ALLEN, 2008; BAXTER, 2009; KEHILY, 2008). Segundo Louro (2007), muitas pessoas consideram a sexualidade como algo que todos/as possuímos 'naturalmente', no entanto, aceitando essa ideia, fica sem sentido argumentar a respeito da sua dimensão social e política ou a respeito do seu carácter construído.

Neste estudo, argumenta-se que o ponto de partida para se estudar a educação em sexualidade (ES) dos/as adolescentes é que o comportamento sexual é, pelo menos em parte, moldado pela aprendizagem social (GIDDENS, 1992; LIMMER, 2010; LOURO, 2007; VILAÇA, 2008; 2012; VILAÇA; SEQUEIRA; JENSEN, 2011) e, neste sentido, o processo de educação em sexualidade envolve uma construção social do conhecimento sobre si próprio/a e sobre os/as outros/as. Baseando-nos em categorias biológicas e sociais, podemos acrescentar que os nossos corpos sexualizados são educados para o género, como consequência das relações que estabelecemos com nós próprios/as e com os/as outros/as no mundo social em que vivemos (MEASOR; TIFFIN; MILLER, 2000).

O género refere-se a uma série de caraterísticas sociais e relacionais que marcam os nossos corpos como pertencendo a uma ou a várias categorias sociais (MEYER, 2011), implicando, por um lado, que a aprendizagem sobre sexualidade é essencial para a aprendizagem sobre o género e a identidade de género e, por outro lado, que a identidade de género afeta as caraterísticas e práticas da nossa sexualidade. Nos últimos anos, alguns estudos sobre o género têm sido fundamentados no construcionismo social que perspetiva o género como uma produção do dia a dia (fazer o género, em vez de pertencer a um género) (HOLMES; MARRA, 2010; NOGUEIRA; NEVES; BARBOSA, 2006; NOGUEIRA, 2004; PYKE; JOHNSON, 2003). De acordo com vários/as investigadores/as, o género é conceptualizado como um desempenho dinâmico, continuamente produzido, 
reproduzido e realmente mudado ao longo da realização pelas pessoas de atos relacionados com as suas características de género, como expressar a afirmação da sua própria identidade de género, ratificar ou desafiar as identidades dos outros e apoiar ou desafiar de várias maneiras os sistemas de relações de género e de privilégios (HOLMES; MARRA, 2010).

Chodorow (1971) explica que as categorias de género ajudam a compreender como é que os indivíduos usam recursos simbólicos para assinalar e expressar a divisão binária em feminino e masculino na sua vida do dia a dia, tais como afirmações, linguagem, objetos, estilos, comportamentos e valores que os colocam dentro de cada uma desses duas categorias, embora os indivíduos selecionem, dentro desses conjuntos de caraterísticas culturalmente disponíveis, aquelas que estão mais identificadas com uma sociedade particular e que significam masculinidade ou feminilidade, e evitam as do género "oposto". Esta abordagem evita a visão determinista que vê os papéis sexuais impostos a indivíduos passivos; uma vez que enfatiza o indivíduo como um participante ativo que seleciona as componentes da sua identidade de género a partir dos elementos culturais a que está exposto (MEASOR; TIFFIN; MILLER, 2000), reforçando a ênfase dada por Foucault (1979) ao facto de termos espaço para proceder a uma automodelação e à possibilidade de se ter uma variedade de posições em relação aos scripts sobre o género e a sexualidade, evidenciando que não possuímos uma identidade (de género ou outras) fixa. Os scripts de género (papéis de género) são as maneiras de se comportar e de pensar que as pessoas têm vindo a associar ao sexo feminino ou masculino (KNUDSON-MARTIN; MAHONEY, 1996; SANCHEZ; FETTEROLF; RUDMAN, 2012).

A visão anterior permite avançar com o conceito de que os aspetos das feminilidades e masculinidades são flexíveis, dinâmicos, ambíguos e evidenciam-se de maneiras previsíveis e imprevisíveis, num processo cujas práticas variam em diferentes culturas e comunidades, rejeitando-se a dicotomia homem/ masculino/ masculinidade - mulher/ feminino/ feminilidade, porque, tal como argumenta Almeida, a "masculinidade e feminilidade não são sobreponíveis ao homem e à mulher respetivamente: são metáforas de poder e capacidade para a ação e atuação, acessíveis por esse motivo ao homem e à mulher" (1997, p. 141, tradução 
nossa). Argumentar que masculinidade e feminilidade são historicamente produzidas está totalmente em desacordo com a visão de que são estabelecidas pela biologia e com uma visão de que o género resulta de uma elaboração social, ampliação e talvez exagero do facto de existir um sexo biológico, “onde a biologia diz 'o que' e a sociedade diz 'como'" (CARRIGAN; CONNEL; LEE, 1985, p. 595, tradução nossa), uma vez que a socialização transcende a determinação biológica, estando a dimensão corporal continuamente presente dentro de uma prática social em que as relações sociais têm continuamente em atenção o corpo (e os processos biológicos como a reprodução) e interagem com ele, constituindo-se nesta interação a sexualidade e o desejo sexual.

Várias investigações têm explorado o que significa assumir, numa variedade de contextos diferentes, as masculinidades (ver por exemplo, CONNEL, 1995; WEDGWOOD, 2009) e as feminilidades (ver por exemplo, ALLEN, 2008; BAXTER, 2009; HOLMES; MARRA, 2010). Connel (1995), discutindo a transição do conceito de "papel masculino" para o de "masculinidades", contrapõe a visão de um conjunto de atitudes e expectativas que definem a masculinidade apropriada (e que não permite compreender questões relacionadas com o poder, a violência ou a desigualdade material que levam a múltiplas formas de masculinidades), a uma visão da configuração da prática (o que realmente fazem, não naquilo que é esperado ou imaginado que façam) em torno da posição dos homens (tem a ver com as suas relações sociais e corpos) na estrutura das relações de género (engloba a economia, o estado, a família e a sexualidade), existindo mais de uma configuração desse tipo em qualquer ordem de género. Os principais elementos de qualquer ordem de género para estudar o género dentro desta perspetiva teórica de Connel são os seguintes: a divisão sexual do trabalho; a estrutura do poder, isto é, a subordinação global da mulher e o domínio do homem; a estrutura da cathexis, isto é, as práticas que concebem e realizam o desejo (ALMEIDA, 1997; WEDGWOOD, 2009).

A masculinidade hegemónica é um elemento central na ordem de género. $\mathrm{Na}$ génese dos debates sobre a masculinidade hegemónica, encontra-se o artigo "Toward a new sociology of masculinity" de Carrigan et al. (1985), no qual os autores defendem que, na masculinidade hegemónica moderna, um sexo (as mulheres) existe como potencial objeto sexual, enquanto o outro sexo (os homens) é negado 
como objeto sexual, o que significa que é a mulher que dá ao homem heterossexual a sua validação sexual, enquanto os homens existem como rivais na esfera sexual e nas outras esferas da vida. Isto significa, que qualquer tipo de falta de poder ou recusa à competição entre os homens, imediatamente leva ao imaginário da homossexualidade e, como consequência, a masculinidade hegemónica é uma variedade particular de masculinidade com a qual os outros (entre eles os rapazes afeminados e o homens homossexuais) estão subordinados e são oprimidos dentro de relações sexuais patriarcais. Esta perspetiva fundamenta uma concepção dinâmica da masculinidade como a estrutura de poder nas relações sociais, em que a masculinidade hegemónica não só oprime as mulheres, como também restringe os homens para se envolverem em certos comportamentos, particularmente aqueles que prejudicariam a posição dominante dos homens como um grupo (CONNELL; MESSERSCHMIDT, 2005; DONALDSON, 1993; HURTADO; SINHA, 2008). Atualmente, a masculinidade hegemónica é definida em função da raça, classe e orientação sexual das identidades sociais privilegiadas (HURTADO; SINHA, 2008). Na perspetiva de Chodorow (1971), os homens jovens, para defenderem a sua masculinidade, usam métodos para lidar com as mulheres que restringem e constrangem as suas oportunidades e experiências, bem como também podem reprimir e esmagar as suas próprias qualidades e aspetos que definem como femininos.

Neste sentido, esta investigação procurou analisar as percepções dos/as professores/as sobre as características de género que afetam a resposta dos/as estudantes na educação em sexualidade (ES), visando conhecer as suas percepções sobre: i) as diferenças de género nas reações aos temas/problemas da ES; ii) a natureza das interações de género durante a ES.

\section{Método}

\section{Amostra}

Foi selecionada uma amostra intencional de variação máxima que integrou um/a um/a professor/a de cada uma das escolas do Distrito de Braga, Portugal, a lecionar do 7ㅇ ao 12ㅇ anos de escolaridade (13 aos 17 anos de idade), com experiência na lecionação de tópicos de ES, em qualquer formato, nos últimos três anos. Estas atividades enquadravam-se no currículo nacional Português para a ES 
(PORTUGAL - MS; ME, 2010), que encoraja os/as professores/as a partir da identificação dos interesses, motivações, preocupações e conhecimentos dos/as alunos/as relacionados com a sexualidade, para desenvolver o seu conhecimento, atitudes e competências em tópicos como: a ética da sexualidade humana; reprodução; métodos contraceptivos; infeções sexualmente transmissíveis (ISTs); prevenção da violência, do abuso físico e sexual e de comportamentos sexuais de risco; maternidade e paternidade na adolescência; interrupções voluntárias de gravidez e prevenção dos maus tratos e das aproximações abusivas.

A amostra foi constituída por 87 entrevistados/as, fundamentalmente do sexo feminino (81,6\%), com uma média de idades de 37 anos (amplitude 23 a 53 anos, $D P=5,9)$. A maior parte tinha mais de 35 anos (61\%) e possuía como grau académico Licenciatura $(86,2 \%)$ ou Mestrado (10,3\%).

\section{Instrumento de recolha de dados}

Os dados foram recolhidos através de uma entrevista semiestruturada, organizada de forma a que os/as professores/as recordassem as atividades de ES que realizaram nos últimos três anos, para verbalizarem as suas percepções sobre: i) as diferenças nas reações dos/as alunos/as aos temas/ problemas de ES; ii) a natureza das interações de género durante o desenvolvimento das atividades de ES.

A primeira dimensão do protocolo da entrevista incluiu perguntas do tipo: "Que preocupações quiseram os/as alunos/as resolver na ES?"; "Que assuntos quiseram aprender?". Na segunda dimensão da entrevista, pediu-se aos/às professores/as para narrarem como é que os/as adolescentes interagiram nas atividades de ES, com questões do tipo: "Como se comportaram durante a realização das atividades de ES?" (ex., tipo de perguntas, dinâmica de trabalho). A entrevista foi validada por três especialistas em educação e pela sua aplicação prévia a uma amostra que não entrou para este estudo.

\section{Tratamento dos resultados}

Todas as entrevistas gravadas foram transcritas na integra, utilizando-se posteriormente o sistema de codificação indutivo de Bardin (1997) para gerar categorias emergentes. 


\section{Apresentação e discussão dos resultados}

\section{Diferenças nas reações dos/as alunos/as à ES}

Preocupações emergentes relacionadas com a sexualidade. Quase a totalidade dos/as professores/as referiu que, embora com mais incidência nas alunas, as mudanças corporais eram uma preocupação na ES (Tabela 1).

Tabela 1. Percepção dos/as professores/as sobre as preocupações dos/as alunos/as relacionadas com a sexualidade $(\mathrm{N}=87)$

\begin{tabular}{|c|c|c|c|c|c|c|}
\hline \multirow[t]{2}{*}{ Preocupações } & \multicolumn{2}{|c|}{$\begin{array}{l}\text { Professoras } \\
(n=71)\end{array}$} & \multicolumn{2}{|c|}{$\begin{array}{l}\text { Professore } \\
s \\
(n=16)\end{array}$} & \multicolumn{2}{|c|}{$\begin{array}{c}\text { Total } \\
(\mathrm{N}=87)\end{array}$} \\
\hline & $f$ & $\%$ & $f$ & $\%$ & $f$ & $\%$ \\
\hline \multicolumn{7}{|l|}{ Mudanças corporais } \\
\hline $\begin{array}{l}\text { O : Mudanças do corpo e imagem } \\
\text { corporal }\end{array}$ & 70 & 98.6 & 15 & 93.8 & 85 & 97,7 \\
\hline $\begin{array}{l}\text { đ: Tamanho do pénis e adequação } \\
\text { sexual }\end{array}$ & 63 & 88.7 & 16 & 100 & 79 & 90,8 \\
\hline $\begin{array}{l}\text { }+ \text { : Tamanho das mamas, adequação } \\
\text { sexual e capacidade para amamentar } \\
\text { } \text { : Menstruação (idade da menarca, }\end{array}$ & 67 & 94.4 & 10 & 62,5 & 77 & 88,5 \\
\hline irregularidades menstruais) & 68 & 95.8 & 15 & 93.8 & 83 & 95,4 \\
\hline \multicolumn{7}{|l|}{$\begin{array}{l}\text { Papéis de género e orientação sexual } \\
\text { †: Clarificar como se devem comportar }\end{array}$} \\
\hline $\begin{array}{l}\text { đ: Clarificar como se sabe se são } \\
\text { homossexuais }\end{array}$ & 15 & 21.1 & 8 & 50.0 & 23 & 26,4 \\
\hline \multicolumn{7}{|l|}{$\begin{array}{l}\text { Despertar do auto-erotismo } \\
\delta /(\text { : Sentir-se culpado/em pecado por }\end{array}$} \\
\hline$ð / Q:$ Clarificar se a masturbação & & 49.3 & 0 & 50.0 & 45 & 4 \\
\hline $\begin{array}{l}\text { prejudica a saúde e a vida sexual a } \\
\text { dois }\end{array}$ & 37 & 52.1 & 8 & 50.0 & 45 & 51,7 \\
\hline \multicolumn{7}{|l|}{ Relações interpessoais } \\
\hline \multicolumn{7}{|l|}{ a) Despertar do hetero-erotismo } \\
\hline$\widehat{\jmath} / Q$ : O primeiro namoro & 69 & 97,2 & 16 & 100 & 85 & 97,7 \\
\hline$\delta / O+: 0$ primeiro beijo & 71 & 100 & 15 & 93.8 & 86 & 98,9 \\
\hline $\begin{array}{l}\delta^{\lambda}: \text { Saber se é normal ter fantasias } \\
\text { sexuais e pensar em sexo }\end{array}$ & 60 & 84.5 & 15 & 93.8 & 75 & 86,2 \\
\hline $\begin{array}{l}\text { ô: Curiosidade sobre o prazer sexual } \\
\text { (toque nos seios, pénis e vagina) }\end{array}$ & 3 & 4.2 & 6 & 37.5 & 9 & 10,3 \\
\hline b) Conflitos inter-pessoais & & & & & & \\
\hline$\widehat{\jmath} / q$ : Relações com os pais (mais tensas) & 71 & 100 & 16 & 100 & 87 & 100 \\
\hline
\end{tabular}




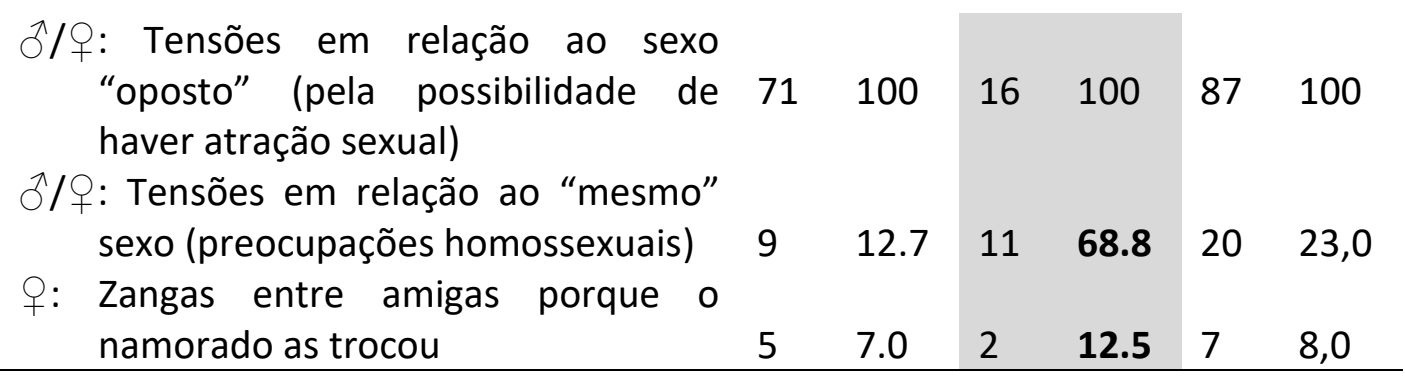

Nota: $\cap$ - alunas; $\hat{\partial}$ - alunos; $\hat{\partial} / q$ - alunas e alunos

Algumas professoras e professores referiram que, por vezes, nas alunas surgiam problemas relacionados com a sua clarificação dos papéis a desempenhar nas relações amorosas (42.3\% e $18.8 \%$ respetivamente), e nos rapazes com a clarificação da orientação sexual (21.1\% e 50.0\% respetivamente).

De acordo com cerca de metade dos/as professores/as, os/as adolescentes queriam clarificar se a masturbação prejudica a saúde e a vida sexual a dois, e a maior parte mostrou sentimentos de culpa em relação à masturbação $(49,4 \%$ do total), como descreveu o professor 02 :

A descoberta do corpo e masturbar-se são sempre preocupações para eles. Depois é também a fase de indecisão, portanto da atração pelo mesmo sexo, não é? E até que ponto são homossexuais, penso que é um problema na nossas sociedade por ter estes preconceitos todos, não é? E depois os miúdos, nesse aspeto, normalmente se detetam alguma coisa que lhes possa parecer mais de menina, por exemplo, se não gostam de jogar à bola ou, como eles passam uma fase de descoberta do corpo, se sentiram qualquer tipo de prazer ocasional com outro rapaz ficam com medo, não é? (Ent. Professor 02)

Da análise das recordações dos/as professores/as sobre as preocupações que os/as adolescentes mostraram nas relações interpessoais na puberdade, emergiram duas categorias: o despertar do heteroerotismo e os conflitos interpessoais.

Praticamente a totalidade dos/as professores/as referiu que os/as alunos/as queriam saber mais sobre o primeiro namoro $(97,7 \%)$ e o primeiro beijo $(98,9 \%)$, se é normal terem fantasias sexuais e pensarem em sexo ( $84.5 \%$ e $93.8 \%)$, e queriam falar sobre prazer sexual (4.2\% e $37.5 \%$ respetivamente). Os/as professores/as também recordavam que os/as adolescentes referiram estar preocupados com conflitos interpessoais, tais como: relações mais tensas com os pais/mães (100\%); 
com o sexo "oposto" por causa da possibilidade de haver atração sexual (100\%) e, alguns, com o "mesmo" sexo por desencadear preocupações homossexuais (23,0\% do total, embora os professores homens referissem mais este aspeto (68.8\%)).

Temas que queriam aprender na ES. Foram vários/as os/as professores/as que contaram episódios que mostram diferenças no tipo de assuntos que os/as alunos/as querem tratar na ES, tal como narrou o seguinte professor:

\begin{abstract}
Eles perguntam muito mais do que elas e o tipo de perguntas que fazem é diferente. Eles perguntam mais sobre os comportamentos sexuais que devem ter, enquanto que elas perguntam sobre a fisiologia, problemas relacionados com a saúde, cancros, quistos, etc. Eles querem muito saber sobre os métodos contraceptivos naturais, saber os dias em que se pode ou não ter relações sexuais, se masturbar-se faz bem à saúde ou se a prejudica. (Ent. Professor 40)
\end{abstract}

Tendo em consideração a totalidade das entrevistas, de acordo com estes/as professores/as na ES a maior parte dos alunos está mais preocupada com o prazer, os mecanismos da relação sexual, contracepção e aborto e a maior parte das alunas com as mudanças corporais, sistemas reprodutores, gravidez e desenvolvimento embrionário, contracepção e prevenção de ISTs, bem como com a autoestima, imagem corporal e competências de assertividade.

Análise da interação corpo, relações sociais e desejo. As percepções dos/as professores/as em relação às preocupações dos/as alunos/as relacionadas com a sua sexualidade são uma evidência de que as relações sociais têm continuamente em atenção o corpo e os processos biológicos e interagem com eles, ultrapassando o determinismo biológico, sendo neste campo de interações que se constituem as sexualidades e o desejo sexual, tal como defendem Carrigan et al. (1985) e Connell (1995). Quando se analisam as preocupações dos/as alunos/as sobre as suas mudanças corporais, podem interrelacionar-se, de uma forma explicita, as suas preocupações anatómicas e fisiológicas (mudanças do corpo versus dos órgãos genitais) com preocupações de sedução (imagem corporal) versus de prazer/ 
desempenho sexual (tamanho do pénis e das mamas como um símbolo sexual e de prazer) e capacidade de reprodução (preocupações com a menstruação). A especificação do desejo sexual nesta fase do despertar da maturidade bio-psicosócio-sexual faz emergir preocupações mais específicas na interação consigo próprio/a (autoerotismo) e com os/as outros/as (hetero-erotismo) e das tensões que essa especificação faz emergir nos relacionamentos interpessoais (conflitos interpessoais).

Refletir sobre evidências de estereótipos de género. De acordo com a percepção dos/as professores/as, há uma seleção de temas estereotipada, que parece corresponder, embora com poucas evidências para o afirmar, a um estereótipo masculino que tende para um interesse, necessidades e funções mais instrumental (prazer, prevenção da gravidez e aborto) e um estereótipo feminino que se inclina para uma tendência mais expressiva, em que a adolescente desempenha um papel mais de suporte, integrativo e de gestão de tensões (gravidez e desenvolvimento embrionário e contracepção e prevenção de ISTs, competências pessoais e sociais).

\section{Natureza das interações de género durante a realização das atividades de educação em sexualidade}

Os/as professores/as recordavam o estilo de interação assertivo como o mais frequente nas alunas durante as atividades de ES. Descreveram que a maior parte delas interagia com facilidade, colocando as suas dúvidas sobre os conteúdos que estavam a ser trabalhados e indicando novos tópicos ou problemas relacionados com a sexualidade que gostavam de abordar. De uma maneira geral, quando Ihes era pedido para clarificarem as suas ideias, faziam-no apresentando bons argumentos científicos, ou, por vezes, do senso comum. Também foi frequente os/as professores/as referirem que as adolescentes, por vezes, explicavam aos colegas rapazes que se deviam calar e não brincar, pois deveriam respeitar a vontade delas em querer aprender. O comportamento dos rapazes foi referido por quase todos/as os/as professores/as como sendo menos assertivo e mais agressivo, dizendo frequentemente que já sabiam o que estava a ser ensinado, respondendo só quando 
"tinham a certeza" que a resposta era cientificamente adequada, ou respondendo de uma forma agressiva para não terem que justificar o que diziam. O excerto da entrevista seguinte mostra um exemplo do comportamento que os/as professores/as se recordavam como mais frequente nos/as alunos/as na sala de aula durante a ES, assertivo nas alunas e agressivo nos alunos:

\begin{abstract}
As miúdas são mais assertivas e têm uma opinião formada, por exemplo, a maioria acha que se deve prevenir, ir ao médico, ir às consultas de planeamento familiar e dizem-no com um grande à-vontade na sala de aula. (...) As alunas utilizam bons argumentos para defender as suas ideias e sabem argumentar. Elas são mais argumentativas e estão mais fundamentadas, eles ainda estão muito na fase do macho, da afirmação pela força, porque não têm argumentos, até porque eles são muito mais ignorantes do que elas. (Ent. professor 03)
\end{abstract}

A percepção de que os alunos têm menos conhecimento científico sobre a morfologia e fisiologia dos sistemas reprodutor masculino e feminino, sobre a gravidez e as ISTs e a sua prevenção, foi referida pela quase totalidade dos/as professores/as.

Neste estudo foi também muito frequente os/as professores/as recordarem que durante as atividades de ES os alunos usavam uma linguagem para intimidar e gozar com as raparigas, bem como se riam delas e não mostravam interesse nos tópicos que estavam relacionados com o sistema reprodutor feminino, como foi muito claro na voz da professora 09:

As meninas estavam muito à-vontade nessas aulas e Enfrentavam com muita naturalidade o tema. Elas faziam observações acerca da menstruação com toda a naturalidade. Os rapazes riam-se delas. Os rapazes são mais infantis, isso é-me claro, eles são mais infantis mas muito tensos. (Ent. Professora 09)

A maior parte dos/as professores/as entrevistados/as explicou a não participação e envolvimento dos alunos nas atividades de ES, pela sua necessidade de mostrar que sabiam muito acerca da sexualidade, o que assumiam como uma 
característica da sua masculinidade, como referiu a professora 38:

Numa primeira parte os rapazes são muito reservados para fazer qualquer tipo de pergunta. São os que fazem as primeiras gracinhas logo na primeira aula mas depois ficam muito reservados. (...) Aos rapazes quase que lhes é exigido, pelo facto de serem rapazes, que têm que ter obrigatoriamente mais conhecimentos, enquanto se as raparigas fizerem perguntas não é visto como ignorância ou falta de feminilidade. Para os rapazes é falta de masculinidade! Os rapazes mesmo quando têm dúvidas retraem-se por acharem que os colegas vão fazer troça! (Ent. Professora 38)

De acordo com estes/as professores/as, as raparigas falavam mais reflexivamente que os rapazes, dando a impressão que pensavam mais cuidadosamente sobre os seus futuros, as suas expectativas nas relações e a importância da família, como referiu o professor 34:

As meninas têm uma maior maturidade e até são capazes de pôr questões mais claras. Tentam mesmo afirmar-se como apresentando mais maturidade e então tentam colaborar. Elas têm mais cuidado, eles não; eles riem-se como quem já sabe tudo, para esconder a ignorância ou então já conversaram com os amigos e acham que resolvem isso entre amigos e que não é preciso aprenderem mais... (Ent. Professor 34)

Implicações na ES da masculinidade hegemónica. A análise da estrutura de poder durante as atividades de ES, baseada nas percepções dos professores, mostrou que a ES proporcionou aos rapazes uma oportunidade para afirmarem a sua masculinidade estereotipada e, como consequência, o seu poder e suposta superioridade. De acordo com os dados obtidos, muitos rapazes de facto não se sentem com poder e involuntariamente mostram-se tímidos durante as atividades de ES, mas a imagem de poder que Ihes é exigida na escola pelos outros/as, faz com que se afirmem a si próprios rindo e berrando com as colegas durante as atividades de ES. Trabalhar competências pessoais, sentimentos ou atitudes de cuidado, bem como aprender sobre o sistema reprodutor feminino, parece ter-lhes parecido 
feminino e não ser aceite numa "masculinidade normal" e, por essa razão, evitaram esses assuntos, mesmo que para isso tivessem que se rir das meninas e não participar nas atividades. Vários estudos anteriores internacionais mostraram vários destes exemplos na ES em contexto escolar (ex., MEASOR et al., 2000; MEASOR, 2004), bem como alguns estudos realizados em Portugal (ex., RODRIGUES; VILAÇA, 2011).

\section{Conclusões e implicações para o futuro}

Os/as professores/as neste estudo mostraram que, de acordo com as suas percepções, os/as alunos/as usam as atividades de ES como recursos simbólicos para construir a sua identidade de género e o seu lugar na hierarquia e, ao fazê-lo, os alunos resistiram a aspetos da ES que transgrediram as suas visões sobre a "masculinidade". A natureza das interações de género durante as aulas de ES parece estar baseada num padrão de masculinidade hegemónica e de uma identidade feminina que parece ser vista pelas meninas como atribuída, havendo nelas a preocupação de conhecer claramente quais são os papéis que lhe estão atribuídos por serem meninas, nomeadamente no seu comportamento sexual. Os rapazes não mostraram interesse nos assuntos ou características pessoais que associam à "feminilidade" e desvalorizaram as questões e interesses das meninas durante as sessões de educação em sexualidade, para mostrar o seu poder e as desvalorizar (por exemplo, riam-se das meninas, faziam gracinhas, não faziam perguntas para não mostrar a sua ignorância).

Para terminar, estes resultados revelam que é essencial trabalhar na formação de professores/as a relação entre género, sexualidade e poder para eles/elas ficarem capacitados/das para refletirem criticamente sobre as reações dos/as alunos/as no sentido de se promover a equidade de género.

\section{Referências}

ALLEN, L. Poles apart? Gender differences in proposals for sexuality education content. Gender and Education, London, v. 20, n. 5, p. 435-450, 2008.

ALMEIDA M. V. DE. Gender, masculinity and power in southern Portugal. Social Anthropology, England and Wales, v. 5, n. 1, p. 141-158, 1997. 
BARDIN, L. Análise de conteúdo. Lisboa: Edições 70, 1997.

BAXTER, J. Constructions of active womanhood and new femininities: From a feminist linguistic perspective, is Sex and the City a modernist or a post-modernist TV text? Women and Language, Wisconsin, v. 32, n. 1, p. 91-98, 2009.

CARRIGAN T.; CONNELL B.; LEE J. Toward a new sociology of masculinity. Theory and Society, Netherlands, v. 14, n. 5, p. 551-604, 1985.

CHODOROW, N. Women in sexist society: studies in power and powerlessness. In: GORNICK V.; NORAN, B. K. (Eds.). Being and doing: a cross-cultural examination of the socialisation of males and females. New York: Basic Books, 1971. p. 259-291.

CONNELL R. W. Políticas da masculinidade. Educação \& Realidade, Porto Alegre, v.20, n. 2, p.185-206, 1995.

CONNELL R. W.; MESSERSCHMIDT J. W. Hegemonic masculinity rethinking the concept. Gender \& Society, London, v. 19, n. 6, December, p. 829-859, 2005.

DONALDSON, M. What Is Hegemonic Masculinity? Theory and Society, v. 22, n. 5, October, p. 643-657, 1993.

FOULCAULT, M. Studies in governmentality. Ideology and Consciousness, v. 6, p. 522, 1979.

GIDDENS, A. The transformation of intimacy: sexuality, love and eroticism in modern societies. Cambridge: Polity, 1992. 212p.

HOLMES J.; MARRA M. Femininity, Feminism and Gendered Discourse: A Selected and Edited Collection of Papers from the Fifth International Language and Gender Association Conference (IGALA5). In: HOLMES J.; MARRA M. (Eds.). Femininity, Feminism and Gendered Discourse. Newcastle: Cambridge Scholars Publishing, 2010. p. 1-18.

HURTADO A.; SINHA, M. More than men: Latino feminist masculinities and intersectionality. Sex Roles, London, New York, v. 59, p. 337-234, 2008.

KEHILY, M. J. Taking centre stage? Girlhood and the contradictions of femininity across three generations. Girlhood Studies, Oxford, New York, v. 1, n. 2, p. 51-71, 2008.

KNUDSON-MARTIN, C.; MAHONEY, A. Gender dilemma and myth in the construction of marital bargains: Issue for marital therapy. Family Process, Southern Gate Chichester, United Kingdom, v. 35, p. 137-153, 1996.

LIMMER, M. Young men, masculinities and sex education. Sex Education: Sexuality, 
Society and Learning, London, v. 10, n. 4, p. 349-358, 2010.

LOURO, G. L. O corpo educado: pedagogias da sexualidade. In: LOURO, G. L.; WEEKS, J.; BRITZMAN, D.; HOOKS, B.; PARKER, R.; BUTLER, J. (Orgs.). Pedagogias da sexualidade. Belo Horizonte: Autêntica Editora, 2007. p. 8-34.

MEASOR, L. Young people's views of sex education: gender, information and knowledge. Sex Education: Sexuality, Society and Learning, London, v. 4, n. 1, p. 153-166, 2004.

MEASOR, L.; TIFFIN, C.; MILLER, K. Young people's views on sex education. London: Routledge/ Falmer, Taylor \& Francis Group, 2000, 193p.

MEYER, E. J. Gender and sexual diversity in schools. London, New York: Springer, 2011. 152p.

NOGUEIRA, C.; NEVES, S.; BARBOSA, C. Fundamentos construcionistas sociais e criticos para o estudo do género. Psicologia: Teoria Investigação e Prática, Braga, v. 2, n. 2, p. 195-209, 2006.

NOGUEIRA, M. da C. Estratégias de intervenção do presente: a psicologia social no contemporâneo. In: GUARESCHI, N. M. de F. (Org.). "Ter" ou "fazer" o género: o dilema das opções epistemológicas em Psicologia Social. Porto Alegre: EDIPUCRS, 2004. p. 249-283.

PORTUGAL - MS; ME - MINISTÉRIOS DA SAÚDE; EDUCAÇÃO. Regulamentação da Lei no 60/2009, de 6 de agosto. Portaria no 196-A/2010 de 09 de abril, D.R. I Série, no 69, p.1170 (2) - 1170 (4), 2010.

PYKE K. D.; JOHNSON D. L. Asian american women and racialized femininities. "Doing" Gender across Cultural Worlds. Gender \& Society, London, v. 17 n. 1, February, p. 33-53, 2003.

RODRIGUES, C. DE J.; VILAÇA, T. Responder às necessidades em educação sexual dos adolescentes: influência do género no desenvolvimento da competência de acção. In: XI CONGRESSO INTERNACIONAL GALEGO-PORTUGUÊS DE PSICOPEDAGOGIA, 2011.Corunha - Espanha. Atas do XI Congresso Internacional Galego-Português de Psicopedagogia. Corunha: Universidade de Corunha, Universidade do Minho, 2011, p. 457-467.

SANCHEZ D. T.; FETTEROLF J. C.; RUDMAN L. A. Eroticizing Inequality in the United States: The Consequences and Determinants of Traditional Gender Role Adherence in Intimate Relationships. Journal of Sex Research, London, v. 49, n. 2-3, p. 168-183, 2012.

VILAÇA, T. Políticas públicas em educação no contexto ibero-americano. In: SOUSA, C. B. G. DE; RIBEIRO, P. R. M. (Org.). Ação e competência para a ação e visibilidade 
do género na educação em sexualidade nas escolas promotoras de saúde. Araraquara: Laboratório Editorial da Faculdade de Ciências e Letras, 2012. p.133157.

VILAÇA, T. The roles of biological Knowledge while exploring action-oriented Knowledge and the S-IVAC methodology in sex education. In: BIOED 2008 INTERNATIONAL CONFERENCE BIOLOGICAL SCIENCES ETHICS AND EDUCATION, 2008. Dijon - France. BioEd 2008 International Conference Biological Sciences Ethics and Education: The Challenges of Sustainable Development. France, Dijon: University of Burgundy, 2008, p. 20.

VILAÇA, T.; SEQUEIRA, M.; JENSEN, B. B. Partnerships between teachers and the community: in-service training on the development of participatory and actionoriented sexual education in schools. Doxa: revista brasileira de Psicologia e Educação, Araraquara, v. 15, n. 1, p. 85-96, 2011.

WEDGWOOD N. Connell's theory of masculinit: its origins and influences on the study of gender. Journal of Gender Studies, Sydney, Australia, v. 18, n. 4, p. 329339, 2009.

Enviado em Abril/2013

Aprovado em Outubro/2013 